\title{
Resenha
}

\section{Midiatização da Tragédia Kiss e a função social da pesquisa em Comunicação}

Resumo: A resenha objetiva descrever a analisar o livro Midiatização da

Tragédia de Santa Maria, publicado em 2018 e organizado por Ada Cristina Machado da Silveira, professora titular da Universidade Federal de Santa Maria (UFSM) e integrante permanente do quadro docente do Programa de Pós-Graduação em Comunicação (POSCOM $\backslash U F S M)$. A coletânea reúne trinta e cinco pesquisadores, nacionais e internacionais, e está dividida em três partes principais, as quais somam vinte capítulos, além do preâmbulo, da apresentação e do posfácio. É a segunda edição da obra, revista e ampliada, sucedendo o ebook publicado no ano de 2014.

Palavras-chave: Pesquisa em Comunicação; Midiatização; Boate Kiss.

O livro nasce em atenção à reflexão sobre a cobertura midiática do incêndio de 27 de janeiro de 2013, na boate Kiss, em Santa Maria (RS), vinculada, sobretudo, à dimensão política que está entrelaçada ao acontecimento trágico que vitimou 242 jovens, e feriu outros tantos, numa noite que seria de festa. Como salienta Silveira (2018, p.16), a obra nasce "numa tentativa de evidenciar a importância social da investigação em Comunicação para um drama coletivo muito próximo à maioria dos autores".

É, portanto, um convite à reflexão, à partir da Comunicação, sobre o acontecimento trágico que abalou os fundamentos da vida social, à esteira do poder hermenêutico que o mesmo possui. Neste sentido, o livro é composto por vinte capítulos, distribuídos em três partes: "Cobertura midiática e discursos privados no espaço público", "Mobilizações e desdobramentos midiáticos" e "Catástrofe biopolítica e narrações do trágico", além do preâmbulo, da apresentação e do posfácio.

$\mathrm{Na}$ primeira parte, os autores se detêm à análise do "desempenho profissional sobre a cobertura do evento, bem como ações e agentes em situações comunicacionais privilegiadas; na segunda seção, o título nasce de expressão da ecologia da mídia "em que agentes a tem como meio de encontro, reforço e reiteração de estratégias solidárias", com ênfase à busca da audiência pela participação e espaços de expressão; por fim, "o enfoque éti-

\footnotetext{
${ }^{1}$ É professor da Universidade de Santa Cruz do Sul (UNISC), doutor pelo Programa de Pós-Graduação em Comunicação e Informação da Universidade Federal do Rio Grande do Sul (UFRGS), graduado em Publicidade e Propaganda e mestre em Comunicação pela Universidade Federal de Santa Maria (UFSM).
} 
co-político detido no alcance primário do poder e não apenas em formas institucionalizadas e já estabilizadas politicamente" (SILVEIRA, 2018, p.20).

A obra inicia com o preâmbulo de Elizabeth Bastos Duarte e Maria Lília Dias de Castro, que resgatam a memória de incêndios anteriores ao da boate Kiss, com causas e desfecho trágico semelhantes. Ao fazerem, iluminam duas questões fundamentais: "por quê, de novo?" e "quando e onde será o próximo?", ante a reincidência das tragédias com (ir) responsabilidades parecidas, situando, neste escopo, a função social das mídias, no papel de denunciar e de participar das transformações necessárias para que tragédias sejam evitadas, no Brasil e fora dele.

$\mathrm{Na}$ apresentação, Ada Cristina Machado da Silveira discorre sobre a idealização e a organização do livro, desde aspectos conceituais inerentes à compreensão do termo midiatização que está ao centro das reflexões reunidas, até a dolorosa tarefa de fazer a cobertura jornalística de uma catástrofe humana que teve 46 horas de cobertura ao vivo em televisão aberta. Em atenção ao esforço desses profissionais, a obra também se justifica. Em seguida, além da deferência aos alunos dos cursos de Comunicação Social da UFSM vitimados pelo incêndio ${ }^{2}$, explana sobre as suas impressões iniciais, desde a sua casa, acerca dos primeiros dias do processo de midiatização da tragédia, marcado por disputas pela informação, inicialmente desencontradas e a reboque das mídias socais, em veículos de comunicação locais, regionais e nacionais; e, por fim, sobre a obra, a inspiração ${ }^{3}$ para o feito, os autores convidados e a relevância dos textos.

O capítulo que abre a primeira seção é de autoria de Antônio Fausto Neto, Anaiara Ventura e Laura Fabrício. Sob o título "Luto no tapume: Andradas, 1925”, o enfoque está na função comunicacional desempenhada pelo tapume colocado em frente ao prédio onde funcionava a boate Kiss e que passou a receber homenagens póstumas às vítimas da tragédia. Na exteriorização de signos que simbolizam a dor da perda de pessoas amadas, através de flores, fotos, mensagens e objetos ali depositados, edifica-se "este monumento construído por operações de sentidos, segundo ação comunicativa que se faz numa outra rede e, sobre outras lógicas entranhadas no cenário e no modo de ser a cidade (2018, p.35). O incêndio é compreendido como um "acontecimento choque" e o tapume-mural desempenha uma função complementar a dos processos midiáticos, numa lógica particular e temporalidade diferenciada.

O texto "Morrer em Santa Maria: as charges de Marco Aurélio sobre a tragédia da boate Kiss", de Adriana Schryver Kurtz, aborda os limites do uso da charge como gênero jornalístico opinativo, cujo formato carrega estreito vínculo com o humor. Para tanto, realiza a análise de charges veiculadas no jornal Zero Hora e os resultados apontam para a dificuldade de realizar a crítica e do uso do humor, num momento de dor extrema, que exige sensibilidade do chargista, ante os sentidos e sentimentos possíveis de serem acionados junto à opinião pública.

No terceiro capítulo, "Noticiar a dor: possibilidades e dificuldades do jornalismo na tragédia de Santa Maria”, Sylvia Debossan Moretzsohn ilumi-
${ }^{2}$ Alana Willers e Emerson Cardozo Paim.

3 Silveira (2018) destaca a obra de Sergio Dayrell Porto, de 2002, elaborada após o acontecimento de 11 de setembro. 
na a relação entre razão e emoção no fazer jornalístico diante da necessidade de noticiar a dor, para discutir os limites possíveis para retratar o drama sem que se ingresse na seara condenável do sensacionalismo midiático, noção, esta, edificada na tradicional oposição razão versus emoção e no conceito de objetividade que orienta os manuais do jornalismo. Em suas linhas finais, diz que "acolher a emoção como um valor para o jornalismo, [...], significa reconhecer uma necessidade e enfrentar uma enorme dificuldade: a de capturar o sentimento sem cair no clichê" (MORETZSOHN, 2018, p. 86), pois, como seria possível eliminar o sofrimento da cobertura do acontecimento trágico em Santa Maria? Ou, nos termos da autora, "como dizer o indizível?", resposta que poderia estar no aceite da emoção como componente do jornalismo e, com isto, incorporar, ou mesmo resgatar, "a sensibilidade dos campos da arte e da literatura ao relato jornalístico" (idem, p. 87).

O quarto capítulo é de autoria de Edileuson Santos de Almeida, Isabel Padilha Guimarães e Ada Cristina Machado da Silveira e recebe o título "A participação do discurso local na cobertura jornalística nacional”. O texto parte da organização centralizada da produção de notícias, prevalecendo a nacionalização sobre a programação local, que praticamente desaparece da grade das emissoras de televisão a partir da década de 1970. Assim, buscam "analisar a participação de uma emissora local em uma cobertura jornalística de envergadura nacional" (ALMEIDA, GUIMARÃES e SILVEIRA, 2018, p.90), tendo como objeto empírico a cobertura ao vivo da RBS TV Santa Maria nos cinco primeiros dias após o incêndio da boate Kiss, com ênfase na análise da participação da primeira repórter local destacada para a realização da cobertura ${ }^{4}$. Os resultados demonstram que a cobertura ao vivo iniciada logo após o incêndio fez com que a imprensa nacional recorresse à participação do local e à atualidade (ao vivo) para o relato dos acontecimentos, invertendo-se a organização convencional da produção de notícias.

No quinto capítulo, "A descoberta do local pelos correspondentes internacionais", Isabel Padilha Guimarães, Janayna Barros e Ada Cristina Machado da Silveira analisam a presença de correspondentes internacionais que realizam a cobertura da tragédia diretamente de Santa Maria, partindo do conceito de local para compreender como se efetuam os vínculos entre os correspondentes internacionais e o espaço de onde noticiam a tragédia. $\mathrm{O}$ corpus empírico é composto por reportagens televisivas de grupos de mídia norte-americanos, de uma rede chinesa e de uma emissora Árabe e, nas considerações finais, apontam que a presença dos profissionais analisados no local "não consiste em apenas fornecer informações, mas participar de uma partilha de emoções para que seus leitores e espectadores tenham elementos humanos para avaliar os acontecimentos" (GUIMARÃES, BARROS e SILVEIRA, 2018, p.117).

O sexto capítulo fecha a primeira parte. Em "O papel dos testemunhos na cobertura em tempo real do caso Kiss", Márcia Frantz Amaral e Juliana Motta refletem sobre as condições de produção de notícias na cobertura de tragédias em tempo real, à partir da análise da participação de fontes testemunhais entrevistadas na cobertura televisiva da RBS TV, nas primeiras 48 

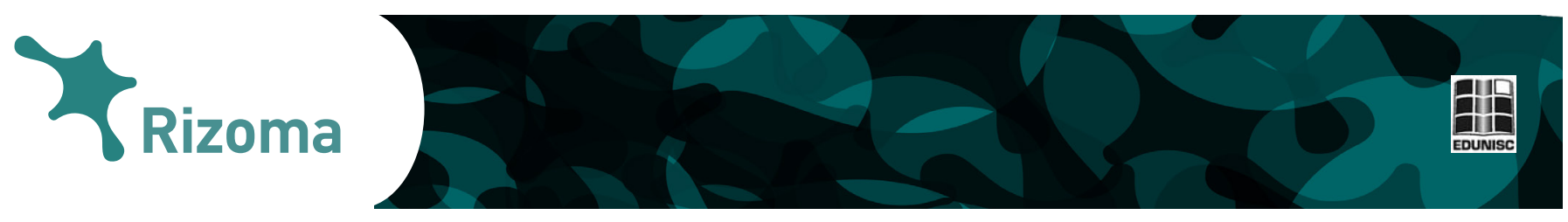

horas desde o incêndio, em comparação com as fontes oficiais e autorizadas. Estas costumam ter maior visibilidade na cobertura de acontecimentos cotidianos e representam posições de poder e de conhecimento. Nas conclusões, relatam que são as emoções que preenchem o discurso das fontes, logo após a tragédia, e que os efeitos de verdade são priorizados à medida que é superado o momento imediato, singular e dramático. Ao final, indicam que transcender este momento, para antecipar a construção discursiva do entorno noticiado, será possível "só se o jornalismo deixar de sofrer as pressões do "tempo real" e priorizar a apuração cuidadosa" (AMARAL e MOTTA, 2018, p. 134).

A parte dois, "Mobilizações e desdobramentos midiáticos", inicia com "Tragédia e solidariedade direcionada no discurso jornalístico, no qual Carlos Orellana e Isabel Padilha Guimarães indagam-se, inicialmente, que, "se a tragédia expõe as contradições da contemporaneidade, como é capaz de ser reveladora dos princípios que constituem a própria sociedade e as formas comunicacionais que nela se realizam? (2018, p.137). O objetivo está em compreender como elementos não-racionais se revelam no discurso jornalístico sobre a tragédia, considerando-se que este contribuiu para a formação de comunidades emocionais solidárias. Ao fim da proposta, indicam que, nestes acontecimentos episódicos, o jornalismo garante a sua legitimidade mesmo ao ancorar o seu discurso em aspectos não racionais, ligados aos sentimentos, pois estes serão catalisadores de rupturas e transformações da experiência social.

O oitavo capítulo, "Mobilização Social no Facebook: conectando solidariedade e justiça no caso da boate Kiss" abre uma sequência de três que abordam as mobilizações sociais em sites de redes sociais, é de autoria de Carolina Moro da Silva e Liliane Dutra Brignol. O texto parte dos conceitos de mobilização social e de redes sociais online, para a análise de como o Facebook é utilizado para a mobilização e ação coletiva, diante das novas formas de mobilização em redes sociais online. A observação via Facebook contempla três eventos - Caminhada da Paz, Caminhada do Luto e Protesto por Justiça. Dos resultados obtidos, relatam que "o Facebook foi apropriado de forma espontânea" e "as ações geraram mobilização em um sentido híbrido entre as redes sociais da internet e o espaço urbano ocupado" (MORO e BRIGNOL, 2018, p. 174).

Em "O perfil do delegado Marcelo Arigony no Facebook: a circulação de sentidos sobre o incêndio na boate Kiss", Adriana Garcia e Carlos Sanchotene analisam os sentidos em circulação sobre o incêndio da boate Kiss, através do perfil do delegado Marcelo Mendes Arigony, no Facebook. Ele foi o responsável pela investigação do caso, e que usou a plataforma de comunicação para emitir opiniões pessoais e interagir com as pessoas, segundo lógicas de mídia. Após a observação, sinalizam que a plataforma comunicacional permite a instituição de novos padrões de construção discursiva, diversificar os emissores e instaurar uma nova arquitetura comunicacional decorrente desses processos de midiatização.

No décimo capítulo, "Jornalismo como sistema de alerta: integração entre mídia social e impressa na Tragédia de Santa Maria”, Gabriela Zago 
e Marco Toledo Bastos analisam o Twitter como um sistema de alerta, no âmbito da hipótese de que o jornalismo se tornou um sistema integrado de alerta que conjuga diferentes mídias na produção de notícias, numa relação de complementaridade entre elas. Para tanto, foi realizado o recorte para tweets que continham links para o jornal Zero Hora, de 25 a 31 de janeiro de 2013. Os resultados apontam para a possibilidade de ilustrar, a partir da hipótese inicial, "como mídia social e impressa podem funcionar de modo coordenado como um sistema de alerta durante eventos de grande comoção" (ZAGO e BASTOS, 2018, p.208).

No capítulo "Drama, mobilização e construção de relatos coerentes em meio ao caos", Ada Cristina Machado da Silveira e Aline Roes Dalmolin abordam os limites da capacidade informativa da estrutura de rede e suas relações assimétricas entre os níveis local, regional e nacional, que é posta em xeque na cobertura jornalística de tragédias e eventos catastróficos. Nesta direção, a questão da regionalização de conteúdos se inscreve na problemática da democratização da mídia, que "passa diretamente pela capacidade de resposta a forças mobilizadoras situadas muito aquém do nacional" (DALMOLIN e SILVEIRA, 2018, p. 212), porém sinalizam que a estrutura em rede de meios está muito distante desta realidade. Das conclusões obtidas, destaca-se que o nível local, na cobertura da tragédia da Kiss, não obedeceu à condição usual de "difuso relator eventual", caracterizando-se como sujeito múltiplo, de fundo.

Em "A recepção de produtos editoriais sobre a tragédia de Santa Maria", André Polga e Ada Cristina Machado da Silveira encerram a segunda parte do livro com a análise das percepções de familiares de vítimas da tragédia sobre os produtos editoriais lançados desde a data do incêndio até meados de março de 2015, com o objetivo de discutir a "importância da mídia e como ela se portou diante da tragédia" (POLGA e SILVEIRA, 2018, p. 229). Para tanto, quatro agentes de mobilização $0^{5}$ foram reunidos em dois grupos focais para discutir quatro produtos editoriais ${ }^{6}$. As conclusões apontam para percepções entendidas como positivas apenas uma delas, a produção editorial acadêmica (até então na versão e-book). Em relação às três primeiras, objetivo principal de lucro e de autopromoção por parte dos autores estão entre as percepções que orientam a crítica.

A terceira parte, "Catástrofe Biopolítica e Narrações do Trágico", começa com "Tragédia Kiss: acontecimento público e armadilhas da imagem", em que Bruno Kegler e Maria Helena Weber analisam a disputa de versões de atores do campo político através da mídia, que explicam, justificam, defendem-se e acusam ante a catástrofe ocorrida. A tragédia é compreendida enquanto acontecimento público (QUÉRÉ, 2011), pois inserida no registro dos problemas públicos. As reflexões são parte do percurso do desenvolvimento da tese doutoral deste autor que elabora esta resenha. A tese intitulada "Redes de comunicação pública, visibilidade e permanência do acontecimento público Tragédia Kiss (Santa Maria, Brasil, 2013)", foi defendida em 2016 no Programa de Pós Graduação em Comunicação e Informação da Universidade Federal do Rio Grande do Sul (PPGCOM\UFRGS) e recebeu menção honrosa no Prêmio Compós de teses e dissertações, em 2017.
${ }^{5}$ Associação dos Familiares de Vítimas e Sobreviventes da Tragédia de Santa Maria (AVTSM), Movimento Santa Maria do Luto à Luta, Movimento Mães de Janeiro e a ONG Para Sempre Cinderelas.

${ }^{6}$ São eles: Kiss: uma porta para o céu, de Lauro Trevisan e lançado em 2013 pela editora da Mente;

Midiatização da Tragédia de Santa Maria (e-book), lançado pela FACOS \UFSM em 2014; Guerreiros de Santa Maria, de Paulinho Oliveira, lançado pela editora Premium em 2014; e "Nossa Nova Caminhada", organizado por Lidiana Betega em 2014, com apoio da gráfica Jacuí. 
O capítulo "Contextos diversos, tragédias similares: a evolução da cobertura jornalística brasileira a partir dos incêndios do Gran Circo norte-americano e da boate Kiss, separados por 50 anos", de Rogério Martins de Souza e Renan Henrique R. Ferreira da Silva, traz análise comparativa para averiguar a evolução dos meios de comunicação entre 1961 e 2013 e, assim, as transformações na cobertura jornalística neste intervalo de cinco décadas entre as duas tragédias. Os resultados obtidos apontam para o deslocamento da exclusividadelsoberania imperativa da televisão à diversidade e à complementaridade das mídias, além da pluralidade de disseminadores de informação através das tecnologias de comunicação mais recentes.

Em "Contar a própria tragédia: o caso Cromanõn", Andrea Estrada analisa a arquitetura discursiva construída pelos próprios sobreviventes da tragédia da Cromanõn, ocorrida em Buenos Aires, em 2004, onde 194 jovens foram mortos. As circunstâncias que ocasionaram o fogo e o cenário da morte eram muito semelhantes naquela tragédia e na da boate Kiss. Com isto, a autora busca a análise do componente passional posto em funcionamento no discurso dos entrevistados ao relatarem o que presenciaram naquela noite. Nas linhas finais, conclui que, para além da percepção, está entrelaçada a dimensão do sofrimento ocasionado pelo fato percebido, de modo que "a enunciação põe em cena a experiência sensível do próprio corpo que, ao se dar conta de algum evento que o afeta, transforma-se em um ser de paixão" (ESTRADA, 2018, p.307).

No décimo sexto capítulo, "Mídias jornalísticas e o trabalho de memória: o incêndio da boate Kiss na primeira página", Leandro Lage propõe a observação da cobertura jornalística da tragédia da Kiss à luz da noção de dever de memória, à partir de Paul Ricoeur ${ }^{7}$, para diferenciar de lugar de memória (NORA, 1993) ${ }^{8}$ e assim problematizar sobre o uso da memória pelo jornalismo.

Em "O trauma atualizado na televisão e no cinema: entre o imediatismo do acontecimento jornalístico e a vontade de memória diante da "Tragédia de Santa Maria”, Cássio dos Santos Tomain, propõe a reflexão sobre a experiência midiática e a afetação resultante dos processos de midiatização da tragédia. Neste sentido, o autor salienta que seu texto resulta deste processo de afetação, pois suas inquietações resultam, especialmente, do que assistira no documentário "Tragédia em Santa Maria", produzido e exibido pelo canal Discovery Channel, e o filme "Janeiro 27", de Luiz Alberto Cassol e Paulo Nascimento, na representação audiovisual da dor e do sofrimento. Neste sentido, através da análise das duas obras fílmicas, problematiza "se as escolhas feitas pelos realizadores dos dois filmes satisfazem uma lógica representativa de verossimilhança, visando produzir um efeito de sentido sobre o acontecimento, ou tem o passado traumático como um dado a ser compreendido" (TOMAIN, 2018, p. 333).

Amarildo Luiz Trevisan, André Luiz de Oliveira Fagundes e Eliana Regina Fritzen Pedroso, em "Santa Maria, trauma e resistência: a experiência estética na dor do outro", buscam respostas para o campo da educação, partindo de Auschwitz enquanto símbolo das catástrofes recentes. O hori-
RICOEUR, P. A memória, a história, o esquecimento. Campinas: Unicamp, 2007.

${ }^{8}$ NORA, P. Entre memória e história: a problemática dos lugares. Proj. História, São Paulo, n. 10, p. $7-28,1993$. 
zonte teórico conta com a obra de Theodor Adorno, em diálogo com obras mais recentes sobre o tema do holocausto. Com isto, buscam um redimensionamento da normatividade e da expressividade do conhecimento, no debruçar-se sobre a crítica do momento presente. Próximo ao desfecho da sua reflexão, afirmam que, diante de acontecimentos trágicos, ou na iminência da ocorrência destes, as duas posições básicas do indivíduo são "emudecer e se resignar, [...]; ou ele pode se voltar contra o tempo presente [...]" (TREVISAN, FAGUNDES e PEDROSO, 2018, p.361). Neste sentido, pode-se ter em tela que tragédias como a da Kiss poderiam ser evitadas à partir de uma formação crítica sobre o lugar do outro na vida social. Tais elementos formadores podem ser tomados de empréstimo da obra de Adorno, que associa a frieza dos campos de concentração à racionalidade típica da modernidade. Neste escopo, colocam a proposta de redimensionamento do conhecimento no confronto, de um lado, do saber-fazer, e, de outro, do dever-ser e do dever-expressar.

Em "Trauma coletivo da perda e as experiências privadas do luto: reflexões sobre o caso de Santa Maria", Milena Freire de Oliveira-Cruz analisa a tragédia da boate Kiss sob a ótica do luto, na relação entre a morte do indivíduo e a morte coletiva, as experiências privadas e as experiências coletivas do luto. Resgatando a frase "Santa Maria nunca mais será a mesma", tantas vezes repetidas após a tragédia, a autora distingue duas experiências do trabalho de luto. A primeira, é a do indivíduo que sofre a perda de um familiar ou amigo e do luto coletivo relacionado às tragédias, que depende de experiências vividas por ele, as quais modificam, também, a sua forma de perceber a vida. A segunda, é a experiência da morte trágica, que produz um sentimento de trauma coletivo, modificando também a experiência e o sentimento de pertença da comunidade ou grupo direta ou indiretamente afetado.

No último capítulo, "Narrações do trágico e horizonte ético", Noeli Dutra Rossatto reflete sobre a distinção entre problemas causados por agentes naturais e os motivados pela ação do homem. Em seu percurso, o autor parte da distinção entre tragédia e catástrofe e finaliza com a reflexão sobre as possibilidades de lição de moral que o mal trágico pode trazer, resgatando a acepção do "trágico" desde a idade média, na relação do termo com o "castigo divino" aos desvios humanos ao curso divino; e, na modernidade, o trágico relacionado à irracionalidade ou particularidade humana que se entrechoca com a razão universal, já num horizonte ético, donde busca subsídios em Hegel ${ }^{9}$.

O posfácio de Eduardo Andrés Vizer finaliza a obra com um texto intenso e envolvente, que convida à reflexão sobre a nossa própria condição existencial, ante o que se projeta ou projetos que entram em suspeição, frente aos sentidos do presente esvaziados pelo impacto da morte trágica de jovens, em Santa Maria. Neste sentido, finaliza com a afirmação de que este livro é, sobretudo, "um hito existencial em la historia de Rio Grande do Sul, de la ciudad de Santa Maria y sus dramáticos imaginários instituyentes" (VIZER, 2018, p.396), conjugadas todas as dimensões analisadas pelos autores reunidos para refletir sobre a catástrofe biopolítica de 27 de janeiro de 2013.
${ }^{9}$ HEGEL, G.W.F. Fenomelogía del Espirito. México: Fondo de Cultura Económica, 1987. 

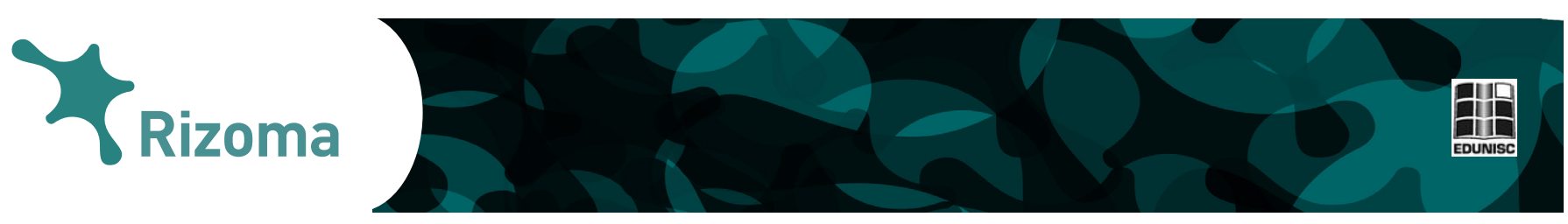

Finalizada a descrição acerca da obra, torna-se notável o caráter interdisciplinar e as múltiplas dimensões e consequências do acontecimento trágico abordadas nos capítulos supracitados. Neste sentido, ilumina-se a sua relevância à pesquisa no campo da comunicação, cujas perspectivas destacamos: o repensar/analisar as práticas profissionais na cobertura jornalística de eventos trágicos; as relações de poder e os limites do público e do privado na sua dimensão biopolítica e frente às disputas pela imagem pública; e as possibilidades comunicacionais e novas formas de mobilização social através das tecnologias de informação e de comunicação mais recentes. Ademais, pode-se assinalar a transcendência deste escopo, pois neste exercício crítico coletivo está intrínseco o convite a repensar sobre quem somos e quem queremos ser, enquanto sociedade, e o que queremos e o que podemos fazer, individual e coletivamente, para alcançarmos esse ideal. Neste sentido, compreendemos que, através desta obra, a pesquisa científica em Comunicação cumpre sua função social. 